\title{
Fuzzy Adaptive Compensation Control for Uncertain Building Structural Systems by Sliding-Mode Technology
}

\author{
Houyao Zhu, ${ }^{1}$ Zicong Chen, ${ }^{2}$ Jianhui Wang $\mathbb{D}^{1},{ }^{1}$ Yunchang Huang, ${ }^{2}$ Wenli Chen, ${ }^{2}$ \\ Zheng Huang, ${ }^{1}$ and Huaqi Zhao ${ }^{3}$ \\ ${ }^{1}$ School of Mechanical and Electrical Engineering, Guangzhou University, Guangzhou 510006, China \\ ${ }^{2}$ School of Automation, Guangdong University of Technology, Guangzhou 510006, China \\ ${ }^{3}$ China United Engineering Corporation Limited, Hangzhou 310051, China
}

Correspondence should be addressed to Jianhui Wang; 87517619@qq.com

Received 6 June 2018; Accepted 2 September 2018; Published 16 October 2018

Guest Editor: Junpei Zhong

Copyright () 2018 Houyao Zhu et al. This is an open access article distributed under the Creative Commons Attribution License, which permits unrestricted use, distribution, and reproduction in any medium, provided the original work is properly cited.

\begin{abstract}
Earthquake is a kind of natural disaster, which will have a great impact on the building structure. In the vibration control field of building structures, the timeliness of system stability is extremely important. In traditional control methods, the timeliness is not paid enough attention for systems with uncertain seismic waves. For setting this problem, fuzzy adaptive compensation control for uncertain building structural systems by sliding-mode technology is proposed. It is combined with fuzzy adaptive control and sliding-mode control to ensure that the system can be stable with satisfied timeliness. Also, saturation function is used to ensure the feasible physical implementation of the control system. Compared with the traditional LQR (linear quadratic regulator) control, the simulation results showed that the proposed method can make the system reach a stable state with rapid convergence performance and has a feasible physical implementation.
\end{abstract}

\section{Introduction}

During the past decades, earthquake has caused serious damage to cities, especially buildings. Thus, it is urgently needed to propose an effective control scheme to protect buildings from earthquake. To deal with building structure vibration easier, normally traditional control methods were researched on a certain earthquake wave; see [1-19]. However, the earthquake wave is uncertain actually. It means that uncertain parts of the control system exist, which are needed to be handled for controller design. By consulting the relevant literature, a fuzzy control scheme can approximate any nonlinear function and have generalization. To handle the uncertain parts, the fuzzy control scheme is proposed to integrate into the controller design; see [20-25].

It is important to prevent the building structure from vibration in a short time, which means that the control system should have a rapid convergence performance. Thus, the sliding-mode control is applied. On the basis of the system's current deviation and various derivative values, the control system can be switched by jumping means in the transient process; see [26-33]. Then, the control system can access the designed sliding plane while the sliding mode motion can be obtained speedily. Therefore, the rapid convergence performance of the control system can be ensured.

On the other hand, the physical implementation of the sliding-mode control method is difficult. Hence, the rapid convergence performance of the control system will be weakened. To ensure that the sliding-mode control method could be physically realized, the saturation function is presented to deal with the problem. In the switching process, it is improving the feasibility of physical implementation by avoiding direct derivation; see [34-42].

Depending on the aforementioned, fuzzy adaptive compensation control for uncertain building structural systems by sliding-mode technology is proposed. Fuzzy adaptive control is applied to compensate for the uncertain parts. Simultaneously, the sliding-mode control method is combined with saturation function to ensure the system rapid convergence performance and the feasibility of physical 
implementation. The main compensatory mechanism and contributions of the proposed schemes are summarized as follows.

Considering the uncertain parts of the control system, which will affect the control effect, adaptive fuzzy control is presented to approximate them. Also, building structural vibration should be suppressed in limited time, or the control is of slight significance. Thus, the commixture of the sliding-mode control and saturation function is proposed to ensure the rapid convergence performance and physical implementation.

The remaining part of the paper is constituted as follows. Models and problem statements are presented. Then, from the simulation results, the proposed method can be proved that it can suppress the uncertain seismic wave effectively by comparing with the LQR control method. They are described in Section 2 and Section 3, respectively. In Section 4 , conclusions are summarized.

\section{The Modeling and Analysis of Building Structure with Earthquake}

2.1. The Modeling and Analysis of Building Structure. The one-layer building structure of interlaminar shear is researched as modeling. When the modeling suffers earthquake, the system can be described as follows:

$$
m \ddot{x}+c \dot{x}+k x=m \ddot{x}_{\mathrm{g}}+u,
$$

where $x$ is the displacement vector of the building structure, $c$ represents the damp, $k$ is the stiffness, $m$ is the mass of the building, $\ddot{x}_{\mathrm{g}}$ is the ground seismic acceleration, and $u$ represents the control input.

Defining a state-space vector,

$$
X=\left[x_{1}, x_{2}\right]^{T},
$$

where $x_{1}=\dot{x}, x_{2}=\ddot{x}$ Space state equations of (1) can be equal with

$$
\dot{X}=A_{\mathrm{r}} X+W_{\mathrm{r}} \ddot{x}_{\mathrm{g}}+B_{\mathrm{r}} U
$$

where

$$
\begin{aligned}
& A_{\mathrm{r}}=\left[\begin{array}{cc}
0 & 1 \\
-\frac{k}{m} & -\frac{c}{m}
\end{array}\right], \\
& W=\left[\begin{array}{l}
0 \\
1
\end{array}\right], \\
& B_{\mathrm{r}}=\left[\begin{array}{l}
0 \\
1 \\
m
\end{array}\right] .
\end{aligned}
$$

According to the rank criterion, the controllability of the building structure with earthquake can be certified.
Thus, the structural vibration can be restrained by designing a control variable.

Setting

$$
u=c \dot{x}+k x+m v
$$

where $v$ is a variable.

Associating with (3) and (2), it can be described as follows:

$$
\dot{X}=\left[\begin{array}{ll}
0 & 1 \\
0 & 0
\end{array}\right] X+\left[\begin{array}{l}
0 \\
1
\end{array}\right]\left(v-\ddot{x}_{\mathrm{g}}\right) \text {. }
$$

The system is composed of $n$ mutually independent subsystems, which can be shown as follows:

$$
\left\{\begin{array}{l}
\dot{x}_{1}=x_{2} \\
\dot{x}_{2}=v-\ddot{x}_{\mathrm{g}} .
\end{array}\right.
$$

2.2. Approximate Function Research. In this section, a fuzzy logic system (FLS) is used to approximate a continuous function $f$ defined on some compact set. The knowledge base for the FLS is comprised of a collection of fuzzy IF-THEN rules of the following form:

$$
\begin{gathered}
R^{n}: \text { If } d_{1} \text { is } F_{1}^{l} \\
\text { If } d_{2} \text { is } F_{2}^{l} \\
\vdots \\
\text { If } d_{n} \text { is } F_{n}^{l} \\
\text { THEN } Y \text { is } G^{l}
\end{gathered}
$$

where $D=\left[d_{1}, d_{2}, \ldots, d_{n}\right]$ is the input of FLS. $Y$ is the output of FLS. $l=1,2,3 \ldots n . F_{n}^{l}$ and $G^{l}$ are fuzzy sets. $R$ and $N$ are the numbers of the rules. Then, the output $Y$ represents as follows:

$$
Y(d)=\frac{\sum_{l=1}^{N} \Phi_{l} \prod_{i=1}^{n} \mu_{F_{i}^{l}}\left(d_{i}\right)}{\sum_{l=1}^{N}\left[\prod_{i=1}^{n} \mu_{F_{i}^{l}}\left(d_{i}\right)\right]},
$$

where $\mu$ is the membership function. $\Phi_{l}=\max _{y \in R g} \mu G^{l}(y)$, $\Phi=\left(\Phi_{1}, \Phi_{2}, \ldots, \Phi_{N}\right)^{T}$. Let $\xi_{l}(D)=\left[\sum_{l=1}^{N} \Pi_{i=1}^{n} \mu_{F_{i}^{l}}\left(d_{i}\right) / \sum_{l=1}^{N}[\right.$ $\left.\left.\Pi_{i=1}^{n} \mu_{F_{i}^{l}}\left(d_{i}\right)\right]\right]$, and $\xi(D)=\left[\xi_{1}(D), \xi_{2}(D), \xi_{3}(d D), \ldots, \xi_{N}(D)\right]$, thus (9) can be described as follows:

$$
Y(d)=\Phi^{T} \xi(D)
$$

For systems seen in (7), the seismic wave $\ddot{x}_{\mathrm{g}}$ is assumed to be known. According to the above analysis, FLS can be 
used to approximate $\ddot{x}_{\mathrm{g}}$. The fuzzy algorithm is designed as follows:

$$
\left\{\begin{array}{l}
\ddot{x}_{\mathrm{g}}=\theta^{* T} \xi(x)+\varepsilon \\
\widehat{\ddot{x}}_{\mathrm{g}}=\widehat{\theta}^{T} \xi(x)
\end{array}\right.
$$

where $\theta^{*}=\arg \min _{\theta \in \Omega}\left[\sup _{x \in R^{2}}\left|\widehat{\ddot{x}}_{\mathrm{g}}-\ddot{x}_{\mathrm{g}}\right|\right], \Omega$ is a set of $\theta$, and $\varepsilon$ is an error. Furthermore, it can be obtained as follows:

$$
\begin{aligned}
\tilde{\ddot{x}}_{\mathrm{g}} & =\ddot{x}_{\mathrm{g}}-\widehat{\ddot{x}}_{\mathrm{g}} \\
& =\theta^{* T} \xi(x)+\varepsilon-\widehat{\theta}^{T} \xi(x) \\
& =\tilde{\theta}^{T} \xi(x)+\varepsilon .
\end{aligned}
$$

Thus, the modeling of the building structure with uncertain earthquakes can be described as

$$
\left\{\begin{array}{l}
\dot{x}_{1}=x_{2} \\
\dot{x}_{2}=v-\widehat{\ddot{x}}_{\mathrm{g}} .
\end{array}\right.
$$

2.3. Controller Design and Analysis of Stability. The error function is designed as

$$
z=b e+\dot{e} \quad b>0
$$

where

$$
\left\{\begin{array}{l}
e=x_{1}-x_{d} \\
\dot{e}=x_{2}-\dot{x}_{\mathrm{d}}
\end{array}\right.
$$
Then,

$c$ is a constant, and $x_{\mathrm{d}}=0$ is the value of expectation.

$$
\dot{z}=b \dot{e}+\ddot{e}=b \dot{e}+\dot{x}_{2} .
$$

According to (7), it can be obtained as follows:

$$
\dot{z}=b \dot{e}+u-\ddot{x}_{\mathrm{g}}
$$

Defining a Lyapunov function,

$$
V=\frac{1}{2} z^{2}+\frac{1}{2 \gamma} \tilde{\theta}^{T} \tilde{\theta}
$$

The derivative of (18) can be obtained:

$$
\dot{V}=z \dot{z}+\frac{1}{\gamma} \tilde{\theta}^{T} \dot{\hat{\theta}}
$$

Deriving from (17),

$$
z \dot{z}=z\left(b \dot{e}+v-\ddot{x}_{\mathrm{g}}-\ddot{x}_{\mathrm{d}}\right)+\frac{1}{\gamma} \tilde{\theta}^{T} \dot{\hat{\theta}} .
$$

The traditional sliding-mode control is based on the switching function, which is designed as follows:

$$
v=-b \dot{e}+\ddot{x}_{\mathrm{d}}+\widehat{\ddot{x}}_{\mathrm{g}}-\eta \operatorname{sgn}(z) .
$$

In order to reduce chattering, the saturation function is applied to substitute the switch function. Thus, the above control law can be transferred as follows:

$$
v=-b \dot{e}+\ddot{x}_{\mathrm{d}}+\widehat{\ddot{x}}_{\mathrm{g}}-\eta \operatorname{sat}(z),
$$

where

$$
\operatorname{sat}(z)= \begin{cases}1 & z>\beta \\ \alpha z & |z| \leq \beta \\ -1 & z<-\beta\end{cases}
$$

In the above equation, $\beta$ represents the border layer, and $\alpha=1 / \beta$.

The derivative of (19) can be obtained as follows:

$$
\begin{aligned}
V & =-\tilde{\theta}^{T} \xi(x)+\varepsilon-\eta \operatorname{sat}(z)+\frac{1}{r} \tilde{\theta}^{T} \dot{\hat{\theta}} \\
& =\varepsilon z-\eta z \cdot \operatorname{sat}(z)+\tilde{\theta}^{T}\left[\frac{1}{r} \dot{\hat{\theta}}-z \xi(x)\right],
\end{aligned}
$$

where $\eta>|\varepsilon|_{\max }$, and $(1 / r) \dot{\widehat{\theta}}-z \xi(x)$, is set, which is equal with $\dot{\hat{\theta}}=r z \xi(x)$. Thus, the equation can be obtained as follows:

$$
\begin{aligned}
\dot{V} & \leq \varepsilon z-\eta z \cdot \operatorname{sat}(z) \\
& \leq \varepsilon z-\eta z .
\end{aligned}
$$

Set $\dot{V} \equiv 0$, then $z \equiv 0$ can be obtained. Thus, according to LaSalle's Principle of invariant set, when $t \longrightarrow \infty, z \longrightarrow 0$. From the above discussion, the system can safely be proved to meet the demands of fast stability.

\section{Simulation of Structure Modeling and Control Methods}

In this section, the system of the building structure is simulated. Then, the LQR control method and fuzzy adaptive compensation control are used to suppress vibration of the building structure, which is subjected to El earthquake wave. The maximum of earthquake acceleration is $a_{\max }=$ $3.417 \mathrm{~m} / \mathrm{s}^{2}$ [19-22]. The parameters of finite-time stable control are $b=0.2, \eta=2$, and $\beta=0.2$. The mass is $3.456 \times 10^{4}$. The damping is $2.4 \times 10^{5}$. The stiffness is $1.75 \times 10^{4}$.

The contrast simulation curves of the displacement, velocity, acceleration response, and control force are shown in Figures 1-4 under no control, LQR control, and proposed control.

According to Table 1, compared with no control, the maximum displacement, velocity, and acceleration, respectively, reduce by $76.1 \%, 53.5 \%$, and $14.9 \%$ by LQR control. 


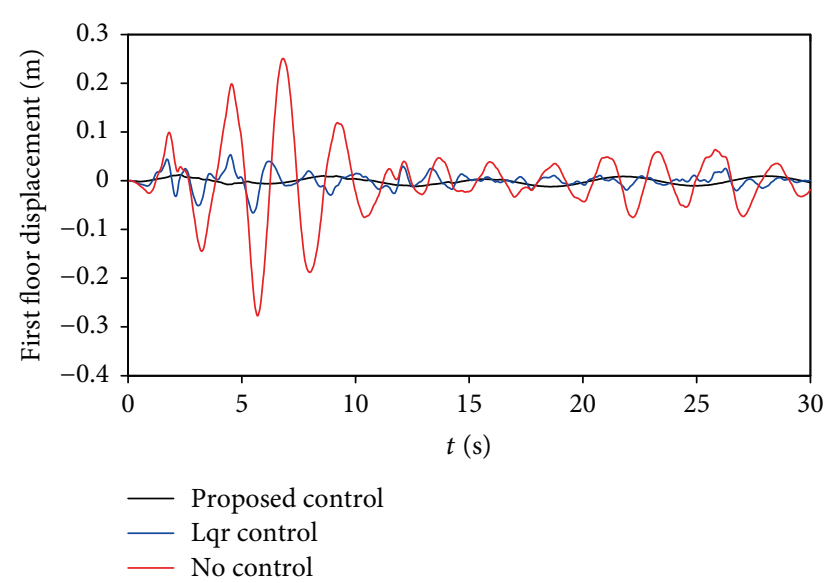

Figure 1: Displacement response example.

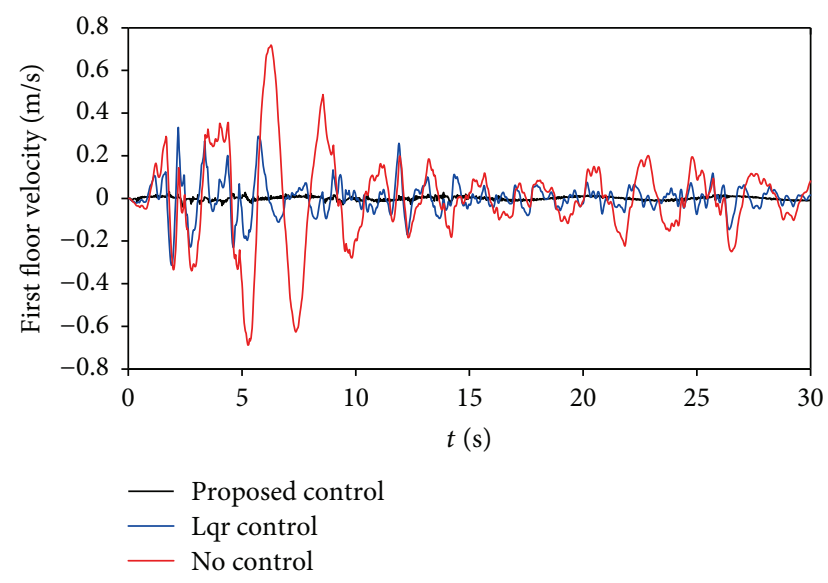

FIgURe 2: Velocity response example.

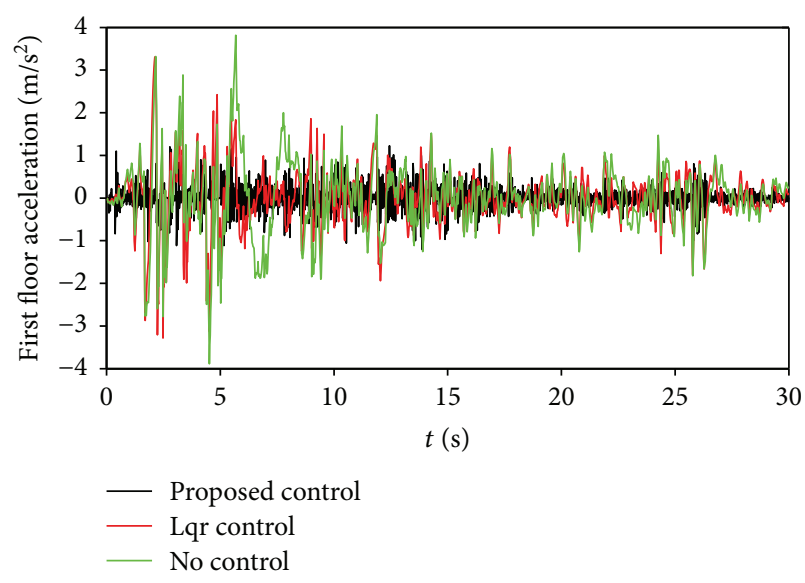

Figure 3: Acceleration response example.

Furthermore, the maximum displacement, velocity, and acceleration, respectively, reduce by $95.6 \%, 95.7 \%$, and $69.5 \%$ by the proposed control.

Therefore, it is obviously shown that vibration of a building structure can be suppressed by LQR and the proposed control method. Also, the proposed control is more

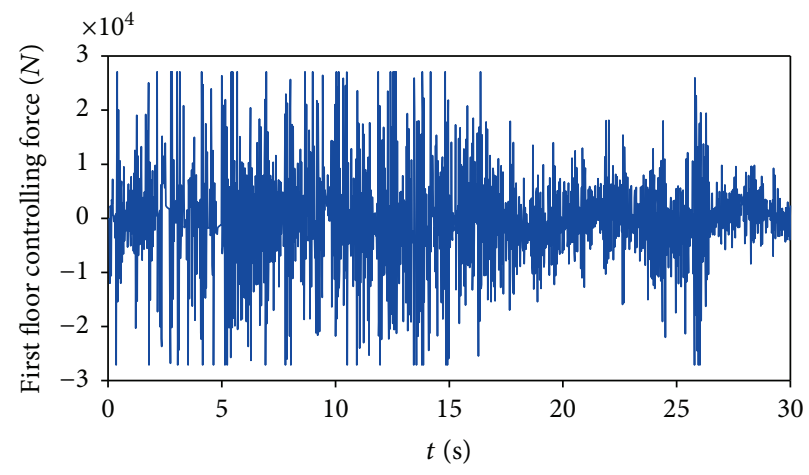

FIgure 4: Controlling force example.

TABle 1: Maximum displacement, velocity, and acceleration of first floor for example.

\begin{tabular}{lccc}
\hline $\begin{array}{l}\text { Control strategy } \\
\text { Parameter }\end{array}$ & Proposed control & LQR control & No control \\
\hline Displacement $(\mathrm{mm})$ & 12 & 66 & 277 \\
Velocity $(\mathrm{m} / \mathrm{s})$ & 0.03 & 0.33 & 0.71 \\
Acceleration $\left(\mathrm{m} / \mathrm{s}^{2}\right)$ & 1.22 & 3.3 & 3.88 \\
\hline
\end{tabular}

effective than the LQR control, and interstory displacement is controlled within a small range. Meanwhile, the issue of chattering from the sliding modeling control is decreased effectively.

\section{Conclusion}

In this paper, a fuzzy adaptive compensation control for uncertain building structural systems by sliding-mode technology is proposed. For most traditional structural vibration control methods, they are difficult to ensure the system to reach a steady state with rapid convergence performance under the influence of the unknown seismic wave. The proposed method adopts fuzzy adaptive control and sliding-mode control to solve the problem. It is ensuring that the system can reach a stable state with rapid convergence performance. At the same time, in order to make the system have a satisfied physical implementation, the saturation function is applied. Finally, the control effect of the proposed method has been compared with the control effect of the LQR control method. Simulation results showed that the proposed method could meet the control requirements. From the above discussion, the feasibility and effectiveness of the proposed method are verified. In this paper, the structural parameters of building structures under unknown seismic waves deserve further study. Research in this part helps us get more accurate results.

\section{Data Availability}

The data used to support the findings of this study are included within the article. 


\section{Conflicts of Interest}

The authors declare that there is no conflict of interest regarding the publication of this paper.

\section{Authors' Contributions}

Zicong Chen is a co-first author.

\section{Acknowledgments}

The authors would like to thank the Associate Editors and anonymous reviewers for numerous constructive comments that have improved the presentation of this paper. This work is supported by the National Natural Science Foundation (NNSF) of China under grant numbers 51775122 and 51505092, Guangzhou City College scientific research project under grant number 1201630173, Science and Technology Planning Project of Guangdong under grant number 2016B090912007, Natural Science Foundation of Guangdong Province, China, under grant number 2015A030308011, and Program of Foshan Innovation Team of Science and Technology under grant number 2015 IT100072.

\section{References}

[1] C. Yang, X. Wang, Z. Li, Y. Li, and C. Y. Su, "Teleoperation control based on combination of wave variable and neural networks," IEEE Transactions on Systems, Man, and Cybernetics: Systems, vol. 47, no. 8, pp. 2125-2136, 2017.

[2] J. Wang, Z. Liu, C. L. P. Chen, and Y. Zhang, "Fuzzy adaptive compensation control of uncertain stochastic nonlinear systems with actuator failures and input hysteresis," IEEE Transactions on Cybernetics, pp. 1-12, 2017.

[3] X. L. Lu, Seismic Theory of Complex High-Rise Buildings with Application, Science Press, Beijing, 2nd edition, 2015.

[4] F. Wang, B. Chen, Y. Sun, and C. Lin, "Finite time control of switched stochastic nonlinear systems," Fuzzy Sets and Systems, 2018.

[5] C. Zhang, X. Lu, J. Li, W. Lu, and Y. Zhou, "The research of the seismic performance of a multi-tower structure," Structural Engineers, vol. 1, pp. 123-127, 2011.

[6] Y.S. Li, C. Z. Xiao, L. F. Jin, and C. Zhang, "Displacement analysis and control study on support of high-rise structures connected with high corridor," China Civil Engineering Journal, vol. 12, pp. 1-8, 2013.

[7] J. Wang, Q. Wang, and K. Ma, "Non-smooth controller design for permanent magnet synchronous motors," Computer Simulation, vol. 33, no. 3, pp. 227-230, 2016.

[8] M. Safdie, “Case study: Marina Bay sands, Singapore," CTBUH Journal, vol. 1, pp. 13-17, 2011.

[9] T. Yong, S. S. Chen, and Q. Y. Tu, "Approaches to structural vibration control for civil engineering," Construction \& Design for Project, vol. 8, pp. 1007-9467, 2011.

[10] Y. Zhou, C. C. Hu, G. X. Zhou, W. S. Lu, X. L. Lu, and P. Chen, "Study on shake table model design method affliction pendulum isolated structures," Structural Engineers, vol. 31, pp. 6-11, 2015.
[11] S.-L. Dai, M. Wang, and C. Wang, "Neural learning control of marine surface vessels with guaranteed transient tracking performance," IEEE Transactions on Industrial Electronics, vol. 63, no. 3, pp. 1717-1727, 2016.

[12] S. L. Wang, W. Liu, and T. Yang, "Experimental study on vibration control of Xiaoyan Pagoda in Xi'an," Journal of Vibration and Shock, vol. 16, pp. 1000-3835, 2017.

[13] F. Wang and X. Y. Zhang, "Adaptive finite time control of nonlinear systems under time-varying actuator failures," IEEE Transactions on Systems, Man, and Cybernetics: Systems, 2018.

[14] C. Yang, X. Wang, L. Cheng, and H. Ma, "Neural-learningbased telerobot control with guaranteed performance," IEEE Transactions on Cybernetics, vol. 47, no. 10, pp. 3148-3159, 2017.

[15] C. He, J. Zhang, Q. Zhao et al., "An electrical-couplingsuppressing MEMS gyroscope with feed-forward coupling compensation and scalable fuzzy control," Science China Information Sciences, vol. 60, no. 4, pp. 180-190, 2017.

[16] F. C. Liu, L. H. Liang, and J. J. Gao, "Fuzzy PID control of space manipulator for both ground alignment and space applications," International Journal of Automation and Computing, vol. 11, no. 4, pp. 353-360, 2014.

[17] Q. Song, X. Dong, Z. Bai, and B. Chen, "Existence for fractional Dirichlet boundary value problem under barrier strip conditions," Journal of Nonlinear Sciences and Applications, vol. 10, no. 7, pp. 3592-3598, 2017.

[18] M. Chen, W. H. Chen, and Q. X. Wu, "Adaptive fuzzy tracking control for a class of uncertain MIMO nonlinear systems using disturbance observer," Science China Information Sciences, vol. 57, no. 1, pp. 1-13, 2014.

[19] H. A. Yousef and M. Hamdy, "Observer-based adaptive fuzzy control for a class of nonlinear time-delay systems," International Journal of Automation and Computing, vol. 10, no. 4, pp. 275-280, 2013.

[20] J. Wang, Z. Liu, C. L. P. Chen, and Y. Zhang, "Event-triggered fuzzy adaptive compensation control for uncertain stochastic nonlinear systems with given transient specification and actuator failures," Fuzzy Sets and Systems, 2018.

[21] S. L. Dai, S. He, H. Lin, and C. Wang, "Platoon formation control with prescribed performance guarantees for USVs," IEEE Transactions on Industrial Electronics, vol. 65, no. 5, pp. 4237-4246, 2018.

[22] F. Wang, B. Chen, C. Lin et al., "Adaptive neural network finite-time output feedback control of quantized nonlinear systems," IEEE Transactions on Cybernetics, vol. 48, no. 6, pp. 1839-1848, 2018.

[23] J. M. Wang, J. J. Liu, B. Ren, and J. Chen, "Sliding mode control to stabilization of cascaded heat PDE-ODE systems subject to boundary control matched disturbance," Automatica, vol. 52, pp. 23-34, 2015.

[24] Z. Q. Li and K. Wang, "Chattering-free of sliding-mode control applied to structural vibration," Computer Engineering and Applications, vol. 11, pp. 229-232, 2017.

[25] J. Yao, "Research on chattering elimination of sliding mode variable structure," Mechanical \& Electrical Engineering Technology, vol. 9, pp. 1009-9492, 2016.

[26] Y. Kong, "Isolation vibration reduction and vibration control analysis of building structures," Architectural Knowledge, vol. 15, pp. 1002-8544, 2017. 
[27] Z. Chen, G. Wen, H. Zhou, and J. Chen, "Generation of grid multi-scroll chaotic attractors via hyperbolic tangent function series," Optik-International Journal for Light and Electron Optics, vol. 130, pp. 594-600, 2017.

[28] S.-L. Dai, C. Wang, and M. Wang, "Dynamic learning from adaptive neural network control of a class of nonaffine nonlinear systems," IEEE Transactions on Neural Networks and Learning Systems, vol. 25, no. 1, pp. 111-123, 2014.

[29] C. Yang, J. Luo, Y. Pan, Z. Liu, and C. Y. Su, "Personalized variable gain control with tremor attenuation for robot teleoperation," IEEE Transactions on Systems, Man, and Cybernetics: Systems, vol. 48, no. 10, pp. 1759-1770, 2018.

[30] X. Li, X. Lin, and Y. Lin, "Lyapunov-type conditions and stochastic differential equations driven by G-Brownian motion," Journal of Mathematical Analysis and Applications, vol. 439, no. 1, pp. 235-255, 2016.

[31] J. M. Wang, H. D. Cheng, Y. Li, and X. N. Zhang, "The geometrical analysis of a predator-prey model with multistate dependent impulses," Journal of Applied Analysis and Computation, vol. 8, pp. 427-442, 2018.

[32] C. Yang, Z. Li, and J. Li, "Trajectory planning and optimized adaptive control for a class of wheeled inverted pendulum vehicle models," IEEE Transactions on Cybernetics, vol. 43, no. 1, pp. 24-36, 2013.

[33] Y. Zhang, H. Dong, X. Zhang, and H. Yang, "Rational solutions and lump solutions to the generalized $(3+1)$-dimensional shallow water-like equation," Computers \& Mathematics with Applications, vol. 73, no. 2, pp. 246-252, 2017.

[34] W. Lv and F. Wang, "Adaptive tracking control for a class of uncertain nonlinear systems with infinite number of actuator failures using neural networks," Advances in Difference Equations, vol. 2017, no. 374, 2017.

[35] Y. Cui, W. Ma, Q. Sun, and X. Su, "New uniqueness results for boundary value problem of fractional differential equation," Nonlinear Analysis: Modelling and Control, vol. 23, pp. 31-39, 2018.

[36] Z. Bai, S. Zhang, S. Sun, and C. Yin, "Monotone iterative method for fractional differential equations," Electronic Journal of Differential Equations, vol. 2016, pp. 1-8, 2016.

[37] J. Wang, C. Zhang, H. Zhu, X. Huang, and L. Zhang, "RBF nonsmooth control method for vibration of building structure with actuator failure," Complexity, vol. 2017, Article ID 2513815, 7 pages, 2017.

[38] S. Zhang, X. Meng, T. Feng, and T. Zhang, "Dynamics analysis and numerical simulations of a stochastic non-autonomous predator-prey system with impulsive effects," Nonlinear Analysis: Hybrid Systems, vol. 26, pp. 19-37, 2017.

[39] H. Dong, T. Chen, L. Chen, and Y. Zhang, "A new integrable symplectic map and the lie point symmetry associated with nonlinear lattice equations," Journal of Nonlinear Sciences and Applications, vol. 9, no. 7, pp. 5107-5118, 2016.

[40] W. Lv, F. Wang, and Y. Li, "Adaptive finite-time tracking control for nonlinear systems with unmodeled dynamics using neural networks," Advances in Difference Equations, vol. 2018, no. $1,2018$.

[41] Q. Wang, J. Wang, X. Huang, and L. Zhang, "Semiactive nonsmooth control for building structure with deep learning," Complexity, vol. 2017, Article ID 6406179, 8 pages, 2017.

[42] J. Wang, H. Cheng, H. Liu, and Y. Wang, "Periodic solution and control optimization of a prey-predator model with two types of harvesting," Advances in Difference Equations, vol. 2018, no. 1, 2018. 


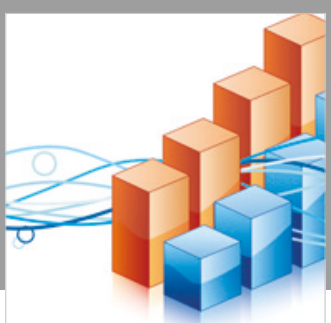

Advances in

Operations Research

\section{-n-m}
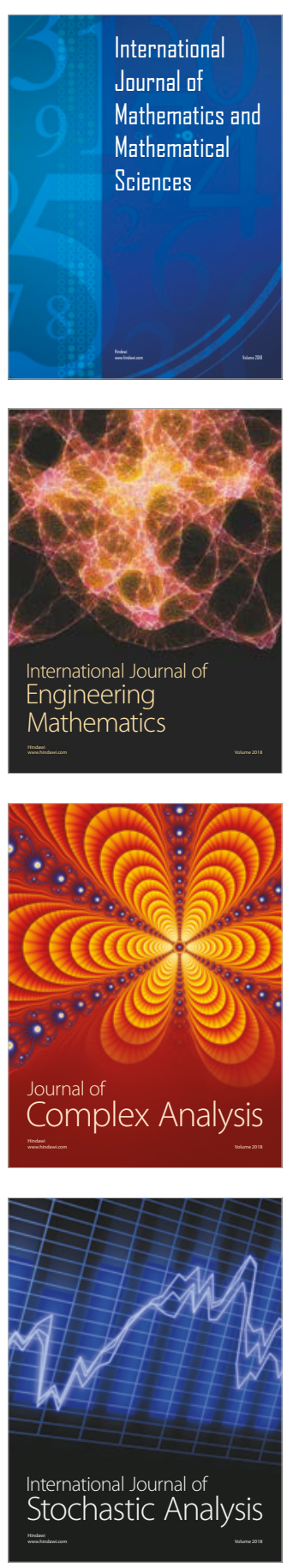
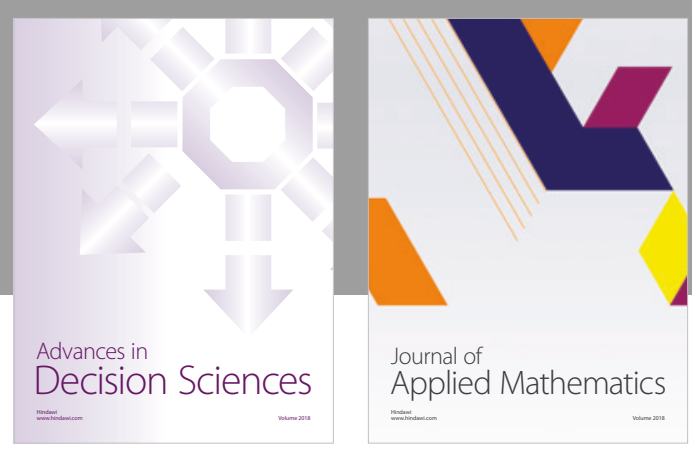

Journal of

Applied Mathematics
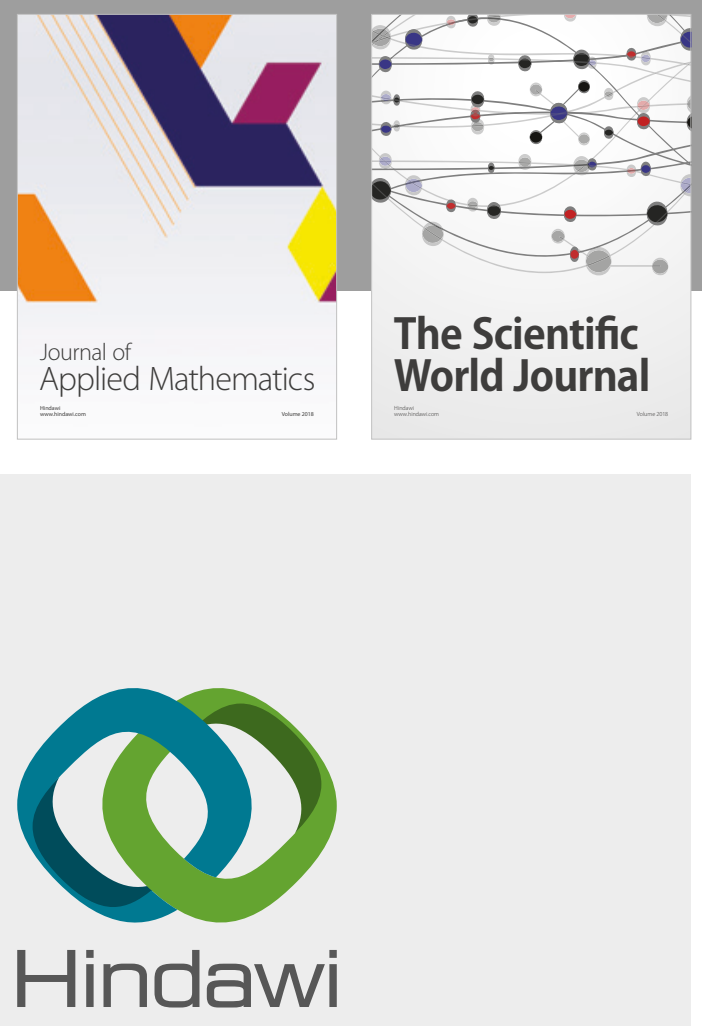

Submit your manuscripts at

www.hindawi.com

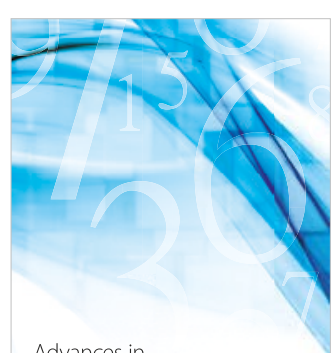

Advances in
Numerical Analysis
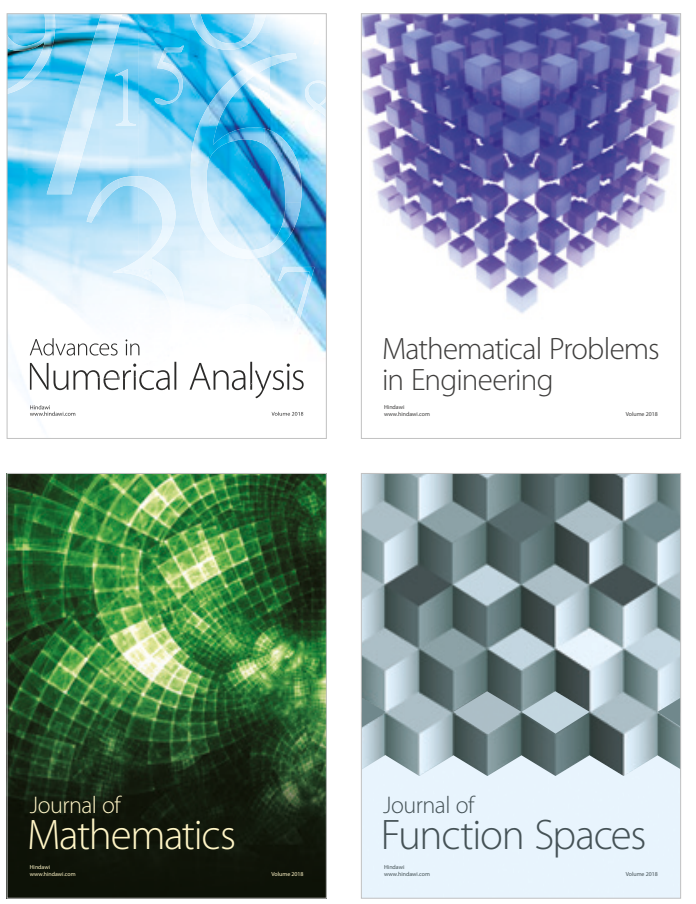

Mathematical Problems in Engineering

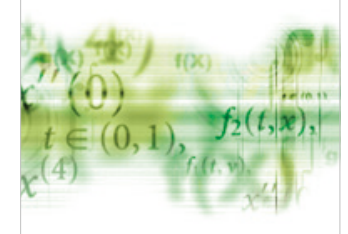

International Journal of

Differential Equations

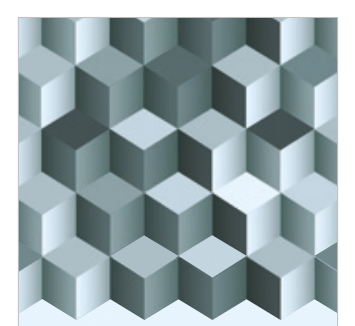

Journal of

Function Spaces
The Scientific

World Journal

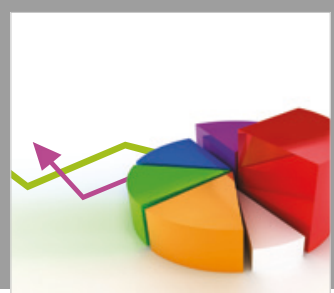

Journal of

Probability and Statistics
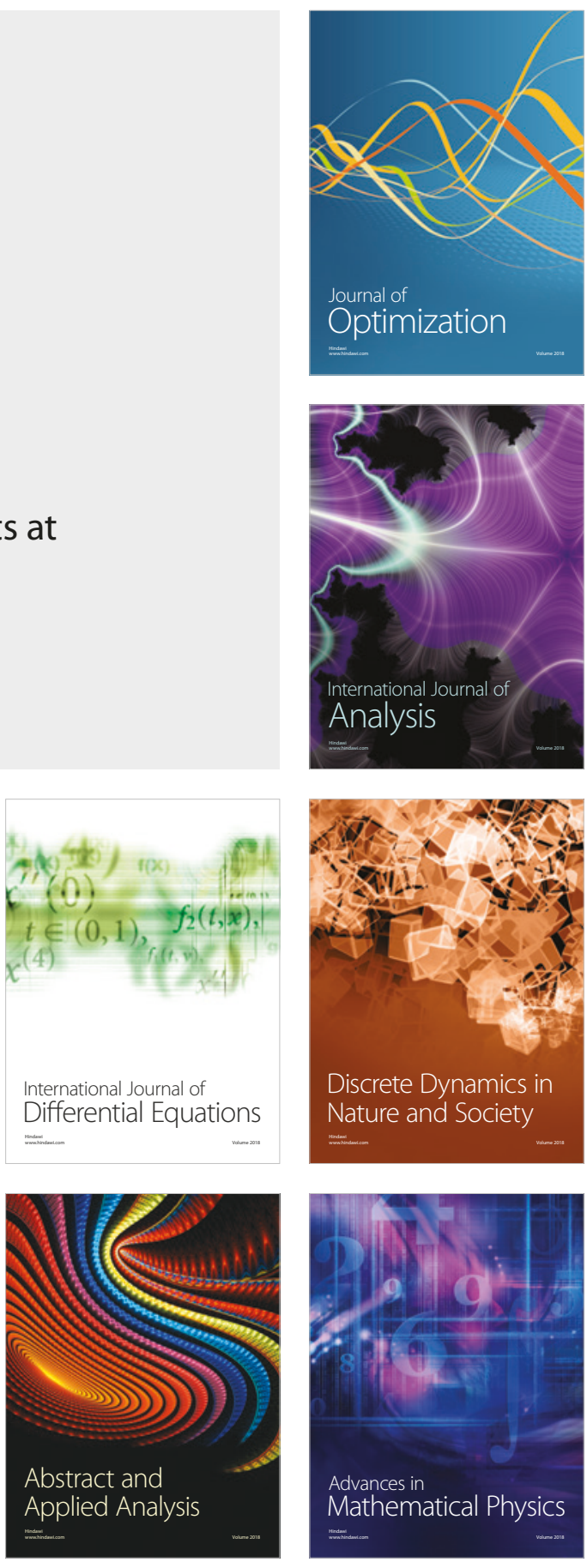